\title{
Independensi Intelectual Capital pada Value creation aset dan modal
}

\author{
${ }^{1}$ Yuni Utami ${ }^{2}$ Adilah Permananingrum ${ }^{3}$ Ira Maya Hapsari \\ Universitas Pancasakti Tegal \\ yuniutami@upstegal.ac.id, adilahpermana@upstegal.ac.id, mayahabibie77@ gmail.com
}

\author{
*Penulis Korespondensi \\ Diajukan : 13 Desember 2021 \\ Disetujui : 23 Desember 2021 \\ Dipublikasi : 4 Januari 2022
}

\section{ABSTRACT}

This study aims to determine the Value Added of Intellectual Capital (Capital Coefficient (CC), Human Capital $(H C)$, Structural Capital (SC) to see the impact on profitability on assets and equity in the Indonesian capital market. The sample taken is stocks that enter in the LQ45 index sector for the 2018-2020 period. The research is quantitative with a descriptive approach, purposive sampling technique and the Eviews 10 analysis tool. The results of the study prove that the Value Added Capital Coefficient (CC) has an effect on Value Creation Assets, while Human Capital (HC) and Structural Capital (SC) has no effect, while from a profitability perspective, the value added capital coefficient (CC) also affects Value Creation Equity, while Human Capital (HC), Structural Capital (SC) does not. effect on Value Creation Equity. These results prove that for companies, which has a high market capitalization and trading volume is influenced by the Value Added Capital Coefficient (CC), while in terms of Human Capital (HC), Structural Capital (SC) has no effect when viewed from the company's Intellectual Capital. The research contribution is that the value added from intellectual capital will lead to value creation both in terms of assets through Return on assets and capital through Return on Equity which is an important element for the company's financial sustainability.

Keywords: Value Added Coefficient Capital (CC), Value Added Human Capital (HC), Value Added Structural Capital (SC), Return On Assets (ROA) dan Return On Equity (ROE)

\section{PENDAHULUAN}

Era reformasi saat ini menerapkan model bisnis yang menciptakan sumber daya intangible lebih bernilai daripada sumberdaya tangible. Janosevis (2009) menyebutkan sumberdaya intangible salah satunya adalah intellectual capital (modal intelektual) yang memiliki dampak terhadap kinerja perusahaan dan pasar. Oleh karena itu, sangatlah penting untuk memahami definisi, konstituen, dan pengukuran intellectual capital, dan kaitannya dengan proses penciptaan nilai (Bontis, 2001 dan Edvinsson \& Sullivan, 1999). Modal intelektual dalam Nahapiet dan Ghosal (1998) mengacu pada pengetahuan dan keterampilan suatu organisasi, komunitas intelektual atau komunitas sosial maupun praktek profesional.

International Federation of Accounting memperkirakan saat ini bahwa 50\% - 90\% nilai perusahaan tidak ditentukan oleh manajemen terhadap aset tetap, melainkan ditentukan oleh manajemen atas modal intelektual. Indonesia sendiri ada fenomena dimana modal intelektual sudah berkembang sejak adanya PSAK No.19 (Revisi 2012) mengenai intangible assets. Dalam aturan tersebut, dikatakan bahwa intangible assets merupakan harta non moneter yang diidentifikasi dan tidak berbentuk wujud fisik atau dapat dimiliki untuk menghasilkan atau menyerahkan barang atau jasa, maupun disewakan kepada pihak lainnya.

Pulic (1997) menciptakan dan mempopulerkan modal intelektual atau ntellectual capital yang diproksikan dengan menggunakan VAIC ${ }^{\text {TM}}$. VAIC ${ }^{\text {TM }}$ terdiri dari beberapa 
komponen utama yaitu Capital Coefficient (CC), Human Capital (HC) dan Structural Capital (SC). Beberapa peneliti, seperti Ting \& Lean (2009) dan Razafindrambinina \& Anggreni (2011), telah menemukan bahwa VAIC mempengaruhi ROA. Di sisi lain, Madinos dkk (2011) tidak dapat menunjukkan hubungan antara komponen VAIC dan ROA. Alipour (2012) juga menemukan bahwa modal intelektual tidak mempengaruhi kinerja keuangan. Adanya alasan tersebut membuat penulis tertarik untuk meneliti lebih lanjut karena penelitian tentang Intellectual capital belum mampu memberikan hasil yang konsisten.

\section{STUDI LITERATUR}

Return of Equity (ROE) merupakan bagaimana perusahaan memiliki kemampuan menghasilkan profit bersih terhadap modal yang dimiliki oleh perusahaan. ROE adalah salah satu indeks profitabilitas yang mewakili perspektif nilai pemilik dan pemegang saham perusahaan (Richieri, dkk., 2008). Rasio ROE semakin tinggi menunjukkan perusahaan menggunakan modal sendiri secara lebih efisien. Return on Assets (ROA) merupakan bagaimana perusahaan mampu menunjukkan laba kotornya terhadap asset totalnya. Rasio ROA yang baik menunjukkan perusahaan melakukan pengelolaan yang baik terhadap tingkat efisiensi atas asset yang dimiliki (Richieri, dkk., 2008).

Intellectual capital merupakan bagaimana perusahaan memperoleh keuntungan dengan cara berinovasi dan meningkatkan layanan, terutama layanan knowledge-intensive (Edvinsson \& Sullivan, 1999). Nilai tambah intellectual capital ada 3 bagian, yaitu capital coeffecient capital (CC), human capital (HC), dan structural capital (SC). Capital Coeficient (CC) merupakan bagian dari modal intelijen yang berfokus pada kemampuan mentransformasi intangible asset menjadi modal yang memiliki value added yang lebih tinggi (Stahle, dkk, 2011). Value creation pada capital coefficient meningkatkan profitabilitas (ROA) dan valuasi pasar (Shiu, 2006). Model Ekonomi Sirkular Value Hill memberikan representasi kursus yang diikuti oleh nilai asset, karena secara khusus, setelah penggunaan utama, masa pakai aset dapat diperpanjang melalui empat fase : Penggunaan kembali, Refurbish, Remanufacture dan Recycle (Radrigo Ghonzales, A, dkk 2021) sehingga muncul hipotesis :

H1 : Capital Coefficient (CC) berpengaruh terhadap Return On Equity (ROE).

H4 : Capital Coefficient (CC) berpengaruh terhadap Return On Asset (ROA).

Human Capital (HC) merupakan kemampuan dan kompetensi yang direpresentasikan oleh value creation, seperti knowledge dan human specific, yang dipunyai oleh semua orang dalam perusahaan yang berkepentingan dan berkemampuan untuk meningkatkan nilai perusahaan (Lazzolino \& Laise, 2013). Value added pada human capital menjelaskan kinerja keuangan melalui value creation, yaitu ROA dan ROE (Richieri, dkk, 2008). Ketika perusahaan memiliki human capital yang terbaik, akan berpengaruh pada kinerja keuangannya, seperti ROA dan ROE.

H2 : Human Capital (HC) berpengaruh terhadap Return On Equity (ROE).

H5 : Human Capital (HC) berpengaruh terhadap Return On Asset (ROA).

Structural Capital (SC) merupakan kemampuan untuk meningkatkan dan berinovasi pada faktor internal, seperti infrastruktur, proses, dan budaya bisnis yang berkaitan dengan modal manusia (Salehi, dkk., 2014). Zoni, Laura dan Federico Pippo (2017 ) menjelaskan bahwa penciptaan nilai yang berasal dari Financial Function (FF) dan peran Chief Financial Officer (CFO) bahwa FF mengadopsi pola yang berbeda untuk menambah nilai bagi pemegang 
saham. keterlibatan FF yang memimpin dalam menetapkan di seluruh fungsi, proses manajemen, manajemen dan pemangku kepentingan. Pola ini juga menciptaan nilai membangun kekuatan untuk bisnis, Sedangkan untuk value added pada structural capital menjelaskan value creation, yaitu ROA dan ROE, melalui pengetahuan non-manusia, seperti teknologi infromasi dan infrastruktur modal yang memiliki value lebih tinggi daripada nilai materialnya. Perusahaan semakin mengadopsi tujuan penciptaan nilai jangka panjang, yang mengintegrasikan nilai finansial, sosial dan lingkungan. paradigma alternatif, berdasarkan pasar adaptif, yang lebih mampu mengejar penciptaan long value added (Schoenmakera, Dirk and Willem Schramade, 2019)

H3 : Structural Capital (SC) berpengaruh terhadap Return On Equity (ROE).

H6 : Structural Capital $\backslash$ (SC) berpengaruh terhadap Return On Asset (ROA).

\section{METODE}

Jenis penelitian ini adalah kuantitatif. Data yang dimbil adalah data sekunder dari annual report melalui www.idx.co.id. Penelitian ini menggunakan obyek dari perusahaan yang sahamnya sudah dicatat di Bursa Efek Indonesia pada indeks LQ45 tahun 2018-2020. Teknik sampling adalah menggunakan metode purposive sampling dengan hasil sampel sebanyak 240 sampel. Alat analisis penelitian menggunakan Eviews versi 10. Model penelitian ini adalah:

1. model penelitian untuk aset

$$
R O A_{i, t}=\alpha_{0}+\beta_{C C} C C_{i, t}+\beta_{H U} H U_{i, t}+\beta_{S C} S C_{i, t}+\varepsilon_{i, t}
$$

2. Model penelitian untuk modal

$$
R O E_{i, t}=\alpha_{0}+\beta_{C C} C C_{i, t}+\beta_{H U} H U_{i, t}+\beta_{S C} S C_{i, t}+\varepsilon_{i, t}
$$

\section{Uji Hipotesis}

HASIL

Hasil Uji hipotesis untuk model penelitian 1 adalah:

\section{Tabel 1 Uji Hipotesis Model 1}

Dependent Variable: ROA

Method: Least Squares

Sample: 1240

Included observations: 240

\begin{tabular}{lrlrl}
\hline \hline \multicolumn{1}{c}{ Variable } & Coefficient & Std. Error & t-Statistic & Prob. \\
\hline \hline C & 1.872766 & 0.508859 & 3.680323 & 0.0006 \\
CC & 58.62220 & 8.171017 & 7.174407 & 0.0000 \\
HC & -0.000913 & 0.001275 & -0.716173 & 0.4777 \\
SC & 0.049094 & 0.047421 & 1.035279 & 0.3062 \\
\hline \hline & & & \\
R-squared & 0.561481 & Mean dependent var & 3.952851 \\
Adjusted R-squared & 0.531581 & S.D. dependent var & 4.020072 \\
S.E. of regression & 2.751382 & Akaike info criterion & 4.941739 \\
Sum squared resid & 333.0845 & Schwarz criterion & 5.097672 \\
Log likelihood & -114.6017 & Hannan-Quinn criter. & 5.000667 \\
F-statistic & 18.77921 & Durbin-Watson stat & 1.602746 \\
Prob(F-statistic) & 0.000000 & &
\end{tabular}


Owner: Riset \& Jurnal Akuntansi

e -ISSN : 2548-9224 |p-ISSN : 2548-7507

Volume 6 Nomor 1, Januari 2022

DOI : https://doi.org/10.33395/owner.v6i1.665

\section{Sumber: data diolah (2021)}

Pada table diatas dapat disimpulkan sebagai berikut :

1. Capital Coefficient (CC) berpengaruh terhadap Return On Assets (ROA). H1 diterima.

2. Human Capital (HC) tidak berpengaruh terhadap Return On Asset (ROA). H2 itolak.

3. Structural Capital (SC) tidak berpengaruh terhadap Return On Asset (ROA). H3 ditolak.

\section{Tabel 2 Uji Hipotesis Model 2}

Dependent Variable: ROE

Method: Least Squares

Sample: 1240

Included observations: 240

\begin{tabular}{crrrr}
\hline \hline \multicolumn{1}{c}{ Variable } & Coefficient & Std. Error & t-Statistic & Prob. \\
\hline \hline C & 3.987044 & 1.809882 & 2.202930 & 0.0329 \\
CC & 142.3473 & 29.06223 & 4.898016 & 0.0000 \\
HC & -0.001510 & 0.004536 & -0.332840 & 0.7408 \\
SC & 0.137803 & 0.168665 & 0.817023 & 0.4183 \\
\hline \hline R-squared & 0.373932 & Mean dependent var & 9.067458 \\
Adjusted R-squared & 0.331246 & S.D. dependent var & 11.96659 \\
S.E. of regression & 9.785966 & Akaike info criterion & 7.479431 \\
Sum squared resid & 4213.666 & Schwarz criterion & 7.635364 \\
Log likelihood & -175.5063 & Hannan-Quinn criter. & 7.538358 \\
F-statistic & 8.759971 & Durbin-Watson stat & 1.119222 \\
Prob(F-statistic) & 0.000114 & &
\end{tabular}

Sumber: data diolah (2021)

Tabel di atas disimpulkan sebagai berikut :

1. Capital Coefficient (CC berpengaruh terhadap Return On Equity (ROE). H4 diterima.

2. Human Capital (HC) tidak berpengaruh terhadap Return On Equity (ROE). H5 ditolak.

3. Structural Capital (SC) tidak berpengaruh terhadap Return On Equity (ROE). H6 ditolak.

\section{Uji F (Simultan)}

Uji ini digunakan untuk mengetahui signifikan pengaruh secara bersama-sama seluruh variabel bebas (independen) terhadap variabel terikatnya (dependen). Hasil uji F adalah sebagai berikut :

Dependent Variable: ROA

Tabel 3 Uji Statistik F Model 1

Method: Least Squares

Sample: 1240

Included observations: 240

\begin{tabular}{ccccc}
\hline \hline Variable & Coefficient & Std. Error & t-Statistic & Prob. \\
\hline \hline C & 1.872766 & 0.508859 & 3.680323 & 0.0006 \\
CC & 58.62220 & 8.171017 & 7.174407 & 0.0000
\end{tabular}


DOI : https://doi.org/10.33395/owner.v6i1.665

\begin{tabular}{lrlll}
\multicolumn{1}{c}{ HC } & -0.000913 & 0.001275 & -0.716173 & 0.4777 \\
\multicolumn{1}{c}{ SC } & 0.049094 & 0.047421 & 1.035279 & 0.3062 \\
\hline \hline R-squared & 0.561481 & Mean dependent var & 3.952851 \\
Adjusted R-squared & 0.531581 & S.D. dependent var & 4.020072 \\
S.E. of regression & 2.751382 & Akaike info criterion & 4.941739 \\
Sum squared resid & 333.0845 & Schwarz criterion & 5.097672 \\
Log likelihood & -114.6017 & Hannan-Quinn criter. & 5.000667 \\
F-statistic & 18.77921 & Durbin-Watson stat & 1.602746 \\
Prob(F-statistic) & 0.000000 & &
\end{tabular}

Sumber: data diolah (2021)

F test menghasilkan nilai sebesar 18,779 dengan signifikansi 0,000. F hitung dari ketiga variable bebas dengan signifikansi 0,05 dan df sebesar 239 adalah 2,6423. F test $>\mathrm{F}$ hitung, dan signifikansi lebih kecil dari 0,05, maka menunjukkan bahwa adanya pengaruh secara Bersama-sama capital coefficient (CC), human capital (HC), dan structural capital (SC) secara bersama-sama terhadap Return on Asset (ROA).

Dependent Variable: ROE

Tabel 4 Uji Statistik F Model 2

Method: Least Squares

Sample: 1240

Included observations: 240

\begin{tabular}{lrrrr}
\hline \hline \multicolumn{1}{c}{ Variable } & Coefficient & Std. Error & t-Statistic & Prob. \\
\hline \hline C & 3.987044 & 1.809882 & 2.202930 & 0.0329 \\
CC & 142.3473 & 29.06223 & 4.898016 & 0.0000 \\
HC & -0.001510 & 0.004536 & -0.332840 & 0.7408 \\
\multicolumn{1}{c}{ SC } & 0.137803 & 0.168665 & 0.817023 & 0.4183 \\
\hline \hline R-squared & 0.373932 & Mean dependent var & 9.067458 \\
Adjusted R-squared & 0.331246 & S.D. dependent var & 11.96659 \\
S.E. of regression & 9.785966 & Akaike info criterion & 7.479431 \\
Sum squared resid & 4213.666 & Schwarz criterion & 7.635364 \\
Log likelihood & -175.5063 & Hannan-Quinn criter. & 7.538358 \\
F-statistic & 8.759971 & Durbin-Watson stat & 1.119222 \\
Prob(F-statistic) & 0.000114 & &
\end{tabular}

Sumber: data diolah (2021)

Uji ANOVA atau F test menghasilkan nilai sebesar 8,7599 dengan signifikansi 0,000. F hitung dari ketiga variable bebas dengan signifikansi 0,05 dan df sebesar 239 adalah 2,6423. $\mathrm{F}$ test $>$ dari $\mathrm{F}$ hitung, dan signifikansi lebih kecil dari 0,05, maka menunjukkan bahwa adanya pengaruh secara Bersama-sama capital coefficient (CC), human capital (HC), dan structural capital (SC) secara bersama-sama terhadap Return on Equity (ROE).

\section{Uji Koefisien Determinasi}

Koefisien determinasi $\left(\mathrm{R}^{2}\right)$ bertujuan untuk digunakan mengukur seberapa jauh kemampuan model dalam menerangkan variasi variabel dependen. Nilai $\mathrm{R}^{2}$ yang kecil berarti kemampuan variabel-variabel independen dalam menjelaskan variasi variabel dependen amat terbatas. 
Owner: Riset \& Jurnal Akuntansi

e-ISSN : 2548-9224 | p-ISSN : 2548-7507

Volume 6 Nomor 1, Januari 2022

DOI : https://doi.org/10.33395/owner.v6i1.665

Dependent Variable: ROA

Tabel 5 Uji R² Model 1

Method: Least Squares

Sample: 1240

Included observations: 240

\begin{tabular}{lrlll}
\hline \hline \multicolumn{1}{c}{ Variable } & Coefficient & Std. Error & t-Statistic & Prob. \\
\hline \hline C & 1.872766 & 0.508859 & 3.680323 & 0.0006 \\
HC & 58.62220 & 8.171017 & 7.174407 & 0.0000 \\
SC & -0.000913 & 0.001275 & -0.716173 & 0.4777 \\
& 0.049094 & 0.047421 & 1.035279 & 0.3062 \\
\hline \hline R-squared & 0.561481 & Mean dependent var & 3.952851 \\
Adjusted R-squared & 0.531581 & S.D. dependent var & 4.020072 \\
S.E. of regression & 2.751382 & Akaike info criterion & 4.941739 \\
Sum squared resid & 333.0845 & Schwarz criterion & 5.097672 \\
Log likelihood & -114.6017 & Hannan-Quinn criter. & 5.000667 \\
F-statistic & 18.77921 & Durbin-Watson stat & 1.602746 \\
Prob(F-statistic) & 0.000000 & & &
\end{tabular}

Sumber: data diolah (2021)

Nilai koefisien determinasi sebesar 0,561 atau 56,1\% mengindikasi bahwa kontribusi variabel independen yaitu capital coefficient (CC), human capital (HC), dan structural capital (SC) terhadap variabel dependen yaitu Return on Asset (ROA) adalah sebesar 56,1\%, sedangkan sisanya sebesar $43,9 \%$ dipengaruhi oleh faktor lain yang tidak disebutkan dalam penelitian ini.

Dependent Variable: ROE

Tabel 6 Uji R $\mathbf{R}^{2}$ Model 2

Method: Least Squares

Sample: 1240

Included observations: 240

\begin{tabular}{crrrr}
\hline \hline \multicolumn{1}{c}{ Variable } & Coefficient & Std. Error & t-Statistic & Prob. \\
\hline \hline C & 3.987044 & 1.809882 & 2.202930 & 0.0329 \\
HC & 142.3473 & 29.06223 & 4.898016 & 0.0000 \\
SC & -0.001510 & 0.004536 & -0.332840 & 0.7408 \\
& 0.137803 & 0.168665 & 0.817023 & 0.4183 \\
\hline \hline R-squared & 0.373932 & Mean dependent var & 9.067458 \\
Adjusted R-squared & 0.331246 & S.D. dependent var & 11.96659 \\
S.E. of regression & 9.785966 & Akaike info criterion & 7.479431 \\
Sum squared resid & 4213.666 & Schwarz criterion & 7.635364 \\
Log likelihood & -175.5063 & Hannan-Quinn criter. & 7.538358 \\
F-statistic & 8.759971 & Durbin-Watson stat & 1.119222 \\
Prob(F-statistic) & 0.000114 & &
\end{tabular}

Sumber: data diolah (2021)

Nilai koefisien determinasi sebesar 0,373 atau 37,3\% mengindikasi bahwa kontribusi variabel independen yaitu capital coefficient (CC), human capital (HC), dan structural capital (SC) terhadap variabel dependen yaitu Return on Equity (ROE) adalah sebesar 37,3\%, sedangkan sisanya sebesar $62,7 \%$ dipengaruhi oleh faktor lain yang tidak disebutkan dalam penelitian ini. 


\section{PEMBAHASAN}

1. Pengaruh Capital Coefficient terhadap Return on Assets

Hasil penelitian menyatakan bahwa capital coefficient mempunyai pengaruh positif terhadap return on assets, dimana nilai koefisien regresi variabel CC sebesar 58,62220 dengan nilai signifikansi sebesar 0.000. Sesuai dengan hasil penelitian. Model Ekonomi Sirkular Value Hill memberikan representasi kusus yang diikuti oleh nilai asset, karena secara khusus, setelah penggunaan utama, masa pakai aset dapat diperpanjang melalui empat fase: Penggunaan kembali, Refurbish, Remanufacture dan Recycle (Radrigo Ghonzales, A, dkk 2021) sedangkan biaya modal dapat ditutupi dari laba operasi bersih setelah pajak perlu yang diinvestasikan untuk menciptakan nilai sehingga pengembalian capital yang telah diinvestasi harus tinggi dari biaya modal rata-rata tertimbang (Charisma \& Encep, 2020). Ini menunjukan bahwa value creation pada capital coefficient meningkatkan profitabilitas (ROA)

2. Pengaruh human capital terhadap return on assets

Dari hasil penelitian ini bahwa human capital tidak berpengaruh terhadap return on assets, dimana nilai koefisien regresi variabel (HC) sebesar 0,000913 dengan nilai signifikansi sebesar 0.4777. Hasil penelitian ini bertentangan dengan (Ulum, 2013) Human Capital (HC) memperlihatkan berapa banyaknya value added yang dihasilkan menggunakan dana yang dipakai untuk tenaga kerja. Dan hubungan HC untuk menimbulkan nilai tambah yang ada di perusahaan. Schoenmakera, dkk. (2019) juga menyatakan ekonomi yang berkelanjutan pada perusahaan mempunyai tujuan untuk penciptaan nilai jangka panjang, hasil integrasi nilai finansial, sosial dan lingkungan. Investor untuk berinvestasi akan menciptaan kinerja secara jangka panjang melalui fungsi sosial keuangan.

3. Pengaruh structural capital terhadap return on assets

Hasil penelitian ini bahwa structural capital tidak memiliki pengaruh terhadap return on assets , dimana nilai koefisien regresi variabel (SC) sebesar 0,049094 dengan nilai signifikansi sebesar 0.3062. Hasil penelitian ini didukung dari penelitian Turmudi (2017) yang menyatakan bahwa structural capital (SC) tidak memiliki pengaruh terhadap return on assets (ROA).

4. Pengaruh capital coefficient $(C C)$ terhadap return on equity ( $R O E)$

Hasil pengujian ini bahwa capital coefficient (CC) memiliki pengaruh terhadap value creation dari return on equity ( $R O E$ ), ditunjukan nilai koefisien regresi variabel CC sebesar 142,3473 dengan tingkat signifikansi sebesar 0.000. Pengaruh tersebut terjadi karena adanya faktor pengaruh yang sama dari kedua variabel tersebut yaitu ekuitas perusahaan, sesuai dengan yang dijelaskan dari (Stahle, dkk, 2011) modal intelijen yang berfokus pada kemampuan mentransformasi intangible asset menjadi modal yang mempunyai value added yang lebih tinggi. dan valuasi pasar (Shiu, 2006). yang menyatakan bahwa capital coefficient $(\mathrm{CC})$ memiliki pengaruh terhadap return on equity (ROE).

5. Pengaruh human capital terhadap return on equity

Dari hasil penelitian ini bahwa human capital tidak memiliki pengaruh terhadap return on equity, dimana nilai koefisien regresi variabel $\mathrm{HC}$ sebesar 0,001510 dengan nilai signifikansi sebesar 0.7408. dari hasil menunjukan hubungan yang negatif dan hasil analisis ini menyimpulkan bahwa value added bagi perusahaan tidak dapat diciptakan oleh karyawan. Turunnya laba terjadi karena memiliki beban karyawan yang tinggi dan 
tidak produktifnya karyawan yang akan berdampak pada turunnya memiliki pengaruh terhadap return on equity (ROE).

6. Pengaruh structural capital terhadap return on equity

Hasil penelitian menyatakan bahwa structural capital tidak memiliki pengaruh terhadap return on equity, dimana nilai koefisien regresi variabel SC sebesar 0,137803 dengan nilai signifikansi sebesar 0.4183. Hasil analisis ini menjelaskan bahwa efesiensi struktur modal belum dapat meningkatkan kkinerja perusahaan dalam memaksimalkan labanya karena hasil penelitian sturctural capital (SC) tidak mempunyai pengaruh terhadap return on equity (ROE). Hal ini berkebalikan dengan Resource Based Theory (RBT) yang menyimpulkan bahwa rasio profitabilitas (ROE) memiliki hubungan yang erat dengan komponen Intellectual Capital.

\section{KESIMPULAN}

Hasil penelitian ini terbukti bahwa Capital Coefficient (CC) berpengaruh terhadap Return on Assets (ROA). Hal ini dibuktikan pengujian parsial diperoleh nilai signifikasi sebesar $0,000<0,05$. Sedangkan Human Capital (HC) dan Structural Capital (SC) tidak berpengaruh terhadap Return on Assets (ROA). Hal tersebut dibuktikan dari hasil pengujian pasial diperoleh nilai signifikasi sebesar 0,4777>0,05 untuk $\mathrm{HC}$ dan hasil pengujian parsial diperoleh signifikansi sebesar 0,306 > 0,05 untu SC. Hasil penelitian juga menunjukan bahwa Capital Coefficient (CC) berpengaruh terhadap Return on Equity (ROE). Hal tersebut dibuktikan dari hasil pengujian pasial diperoleh nilai signifikasi sebesar $0,000<0,05$. Sedangkan nilai Human Capital (HC) dan Structural Capital (SC) tidak berpengaruh terhadap Return on Equity (ROE) yaitu dengan dibuktikan dari hasil pengujian pasial diperoleh nilai signifikasi sebesar 0,741 > 0,05 untuk HC dan hasil pengujian pasial diperoleh nilai signifikasi sebesar 0,418>0,05 untuk SC. Kontribusi penelitian adalah value added dari intelectual capital akan memunculkan value creation yang baik dari sisi asset melalui Return on assets maupun modal melalui Return on Equity yang merupakan unsur penting bagi keberlangsungan finansial perusahaan.

\section{REFERENSI}

Alipour, M. (2012). The effect of intellectual capital on firm performance: an investigation of Iran insurance companies, Measuring Business Excellence, Vol. 16 No. 1, 53-66.

Charisma, Bryan and Encep Amir, (2020). "Economic Value-Added Creation by Optimizing Capital Structure in Project Finance "International Journal of Applied Research in Management and Economics ISSN 2538-8053.

Edvinsson, Leif, \& Sullivan, Patrick. (1996). developing a model for managing intellectual capital. European Management Journal Vol. 14 No. 4, 356-364.

Freeman, R. E., \& Reed. (1984). Stockholder and Stakeholder a new Perspective On Coorporate Governance. Management Review, 25, 88-106.

Guthrie, J., Petty, R., \& Ricceri, F. (2006). The Voluntary Reporting of Intellectual Capital. jurnal of intellectual capital, 7, 254-271.

Lazzolino, Gianpaolo, \& Laise, Domenico. (2013), Value added intellectual coefficient (VAIC): a methodological and critical review. Journal of Intellectual Capital, Vol. 14 No. 4, 547-563.

Maditinos, D., Chatzoudes, D., Tsairidis, C. and Theriou, G. (2011), The impact of intellectual capital on firms' market value and financial performance, Journal of Intellectual Capital, Vol. 12 No. 1, 132-151. 
Meek, G., \& Gray, S. (1988). The Value Added Staament an Innovation for the US companies. 83, 185-216. Https://search.proquest.com

Nahapiet, J., \& Ghosal, S. (1998). Social Capital, Intellectual Capital, and the Organizational Advantage. Academy of Management Riview, 23, 77. Https://citeseerx.ist.psu.edu/

Radrigo Ghonzales, A, Alfredo Grau-Grau * and Inmaculada Bel-Oms. Circular Economy and Value Creation: Sustainable Finance with a Real Options Approach, Sustainability 2021, 13, 7973. https://doi.org/10.3390/su13147973.

Razafindrambinina, D. and Anggreni, T. (2011). Intellectual capital and corporate financial performance of selected listed companies in Indonesia, Malaysian Journal of Economic Studies, Vol. 48 No. 1, 61-77.

Riahi, B. (2003). Intellectual Capital and Firm Performance of US Multinational Firms A study of the resource based and stakeholder views. Journal of Intellectual Capital, 4, 215226.Https://www.researchgate.net/publication/

Richieri, Flavio L., Basso, Leonardo F.C., Martin, Diogenes D. L. (2008). Intellectual capital and the creation of value in Brazilian companies.

Salehi, Mahdi, Enayati, Gholamreza, Javadi, Parisa. (2014). the relationship between intellectual capital with economic value added and financial performance. Iranian Journal of Management Studied (IJMS) Vol. 7, No. 2, 259-283.

Schoenmakera, Dirk and Willem Schramade (2019), Investing For Long-Term Value Creation Journal Of Sustainable Finance \& Investment 2019, Vol. 9, No. 4, 356-377.

Shiu, Huei-Jen. (2006). The application of the value added intellectual coefficient to measure corporate performance: evidence from technological firm. International Journal of Management, Vol. 23, No. 2, 356-365.

Stahle, Pirjo, Stahle, Sten, Aho, Samuli. (2011). Value added intellectual coefficient (VAIC): a critical analysis. Journal of Intellectual Capital Vol. 12, No. 4., 531-551.

Stewart, T. A. (1998). Intellectual Capital: The New Wealth of Organizations. New York: Nicholas Brealey.

Ting, W.K.I. dan Lean, H.H. (2009). Intellectual capital performance of financial institutions in Malaysia”, Journal of Intellectual Capital, Vol. 10 No. 4, 588-599.

Turmudi, A. Z. (2017). Analisis Pengaruh Intellectual Capital terhadap Return On Equity (ROE) dan Return On Asset (ROA) Pada Perusahaan Yang Masuk Dalam Indeks LQ45. STIE Perbanas Surabaya, 2.

Ulum, I. (2013). IB-VAIC Model Pengukuran Kinerja Capital Perbankan Syariah di Indonesia . Jurnal Inferensi (terakreditasi), 7, 183-204.

Watts, R. L., \& J.L, Z. (1978). Towards a Positive Theory of The Determination of Accounting Standards. The Accounting Review, 53, 112-134. Https://www.excellant.be/Theori/

Laura Zoni, Federico Pippo, (2017) CFO and Finance function: what matters in value creation, Journal of Accounting \& Organizational Change, Vol. 13 Issue: 2. 